\title{
Underwater Radiated Noise from Hydrofoils in Coastal Water
}

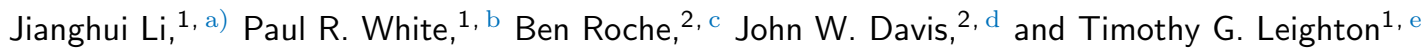 \\ ${ }^{1}$ Institute of Sound and Vibration Research, University of Southampton, Southampton, SO17 1BJ, \\ U.K. \\ ${ }^{2}$ Ocean and Earth Science, University of Southampton, National Oceanography Centre, Southamp- \\ ton, $S O 143 Z H, U . K$.
}

Underwater noise from commercial shipping throughout the oceans has been increasing over the past decades and the environmental impact of this noise remains an area of great uncertainty. This has led to the measurement of noise from commercial vessels in order to understand the impacts that they may engender. Hydrofoils are used by ferries in various locations around the world and locally may be a significant contributing factor of the soundscape. However, the investigation on underwater radiated noise from the activity of hydrofoils in the field has not been widely conducted. This article is an attempt to characterize the noise from hydrofoils in the field. Detailed measurements in the coastal water close to the Panarea port, Italy are reported. The investigation describes the broadband frequency spectrum with the main energy approximately centered on 30-130 Hz but covering frequencies up to tens of $\mathrm{kHz}$. A key result was that the spectrum of the noise varied between the three stages (displacement, transition, and foiling) of the hydrofoils heading into or out of the port.

(C)2019 Acoustical Society of America. [http://dx.doi.org(DOI number)]

$[\mathrm{XYZ}]$

\section{INTRODUCTION}

The negative environmental impacts of anthropogenic underwater noise have been an area of increasing research activity in recent decades, as emphasized by the International Maritime Organization (IMO) and Marine Environmental Protection Committee (MEPC) (Aktas et al., 2016). There are concerns across a range of taxa, but the greatest research effort has focussed on the impacts on cetaceans (Holt et al., 2009; Nowacek et al., 2007; Parks et al., 2007; Richardson and Würsig, 1997). This does not mean that one should discount the potential impacts on other taxa, significant work has demonstrated impacts on pinnipeds, fish, cephalopods and invertebrates (Chen et al., 2017; Deleau et al., 2019; Halliday et al., 2017; Merchant et al., 2014' 2012b; Piper et al., 2019; Solan et al., 2016; Williams et al., 2014, 2018). Most early work in this area has considered acute impacts, such as those associated with the use of military sonar (Rendell and Gordon, 1999), marine construction (Dahl et al., 2015; Nedwell et al., 2003) and seismic surveys (Bailey et al., 2010). However, a great deal of work considering the effect of chronic exposures has been undertaken, with most of the emphasis being placed on the impact of noise associated with shipping (Allen et al.,

\footnotetext{
a) J.Li@soton.ac.uk

b)P.R.White@soton.ac.uk

c)br4g13@soton.ac.uk

d) jwd1@noc.soton.ac.uk

e)T.G.Leighton@soton.ac.uk
}

2012; Hermannsen et al., 2014; McKenna et al., 2012; Merchant et al., 2012b). Consequently, the measurement and modelling of ship noise has become one focus of interest to the broad academic community (Andrew et al., 2011; Arveson and Vendittis, 2000; Erbe et al., 2012; Gray and Greeley, 1980; Li et al., 2019a; McKenna et al., 2013; Merchant et al., 2012a; Wales and Heitmeyer, 2002; Wittekind, 2014): previously it had been widely studied in a military context since before the Second World War (Urick, 1983).

Various studies have reported measurements of noise from a variety of commercial vessels (McKenna et al., 2012; Merchant et al., 2012b) and there has been an associated development of international standards for such measurements (Audoly, 2016; Badino et al., 2012). The measurements of commercial ships have naturally focused on the most common forms of large marine vessels (Matveev, 2002; McKenna et al., 2012). For most ports handling large amounts of cargo in industrialized nations, these vessels are the ones which are major contributors to the ambient noise in the ocean in the frequency band 10-300 Hz (Erbe et al., 2013; Fillinger et al., 2010; Lani et al., 2013; Urick, 2013). However, far less is known about the radiated noise from non-conventionally powered vessels, such as hydrofoils, which radiate high level noise in much wider frequency band, particularly in the water coastal area close to a port/harbour.

Hydrofoils are a common choice in some parts of the world for use as passenger ferries where speed is a critical factor. The body of hydrofoil ships is supported by wing-like structures (foils) which, when the vessel reaches a sufficient speed, lifts the body of the craft out of the 
water greatly reducing drag and so increasing the top speed. Typically, hydrofoils can cruise at speeds of up to 50 knots $(25 \mathrm{~m} / \mathrm{s})$ and operate in seas with wave heights of up to $2-3 \mathrm{~m}$. The design of a hydrofoil means there are two distinct operating conditions: low speed manoeuvring, with its body in the water, when the hydrofoil behaves like most vessels, and high-speed cruising, when the body is lifted from the water. The underwater radiated noise level in these two modes and the speed change between the two modes are significantly different. The mechanisms for noise generation in the low speed condition is very similar to that of a conventional ship, albeit with the propeller at greater relative depth. In the high-speed condition the acoustic signature of the craft is likely to be significantly different to that of conventional vessels.

This paper quantifies the underwater acoustic levels radiated from ships, taking the in situ passive acoustic measurements of passing ships for a range of operating conditions and ship directions. In this way, the paper reports measurements of the underwater radiated noise from hydrofoils in shallow coastal water. We took an opportunistic approach to measure radiated noise from hydrofoils transiting the Panarea southeastern water channel, Italy. Hydrofoils use the channel when travelling towards and away from the island for tourism. A passive acoustic ship noise experiment was conducted offshore of the island, with an acoustic recorder positioned at a depth of $7 \mathrm{~m}$ in the water column near the port. Acoustic data were recorded, and combined with land-based monitoring video and Automatic Identification System (AIS) vessel tracking data, from which the acoustic signatures of individual ships at different stages and direction of travel could be determined.

This paper is organized as follows. Section II describes the acoustic recording and signal processing, and Section III shows the measurement results. Section IV completes the paper with discussions.

\section{METHODS}

This section describes methods of experimental deployment, acoustic recording, data processing and propagation channel modelling.

\section{A. Deployment}

To measure the radiated noise from hydrofoils, we conducted an opportunistic in situ noise measurement in the southeastern water channel of the island Panarea, Italy on 14th May 2018. Fig. 1 shows a map of the Panarea southeastern water channel. Panarea is one of the volcanic Aeolian islands north of Sicily. Hydrofoils are used as ferries in the region and visit Panarea on a daily basis sailing along through the southwest water channel between the island and the rocks le Formiche approximately $1 \mathrm{~km}$ to the land-based observation (video camera) station.

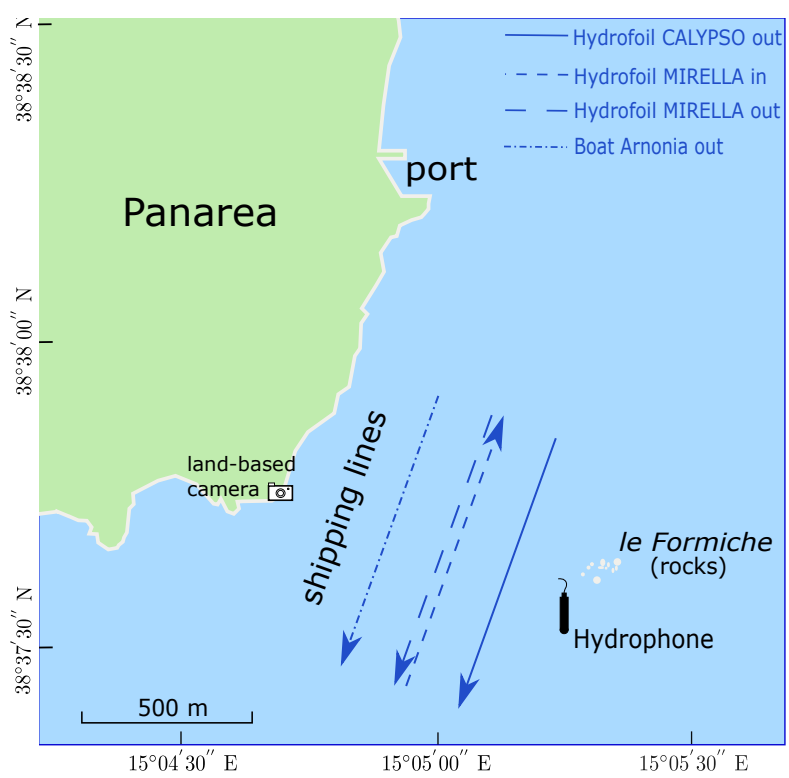

FIG. 1. Map of the Panarea southeastern water shipping channel. The position of hydrophone and the relative position/direction of shipping path are shown. The le Formiche are rocks $1 \mathrm{~km}$ to the southeast of Panarea (camera). The hydrophone was deployed at position $\left(38^{\circ} 37^{\prime} 36^{\prime \prime} \mathrm{N}\right.$, $\left.15^{\circ} 04^{\prime} 57^{\prime \prime} \mathrm{E}\right), 128 \mathrm{~m}$ southwest to the rocks, $7 \mathrm{~m}$ to the sea surface, and $8 \mathrm{~m}$ to the seafloor. (camera: land-based visual observation station with video monitoring).

An acoustic recorder (Song meter SM4M) containing a hydrophone (Wildlife Acoustics, Maynard, United States; receive sensitivity of $-164.5 \mathrm{~dB}$ re: $1 \mathrm{~V} / \mu \mathrm{Pa}$ ) was deployed in the water channel. It was positioned $855 \mathrm{~m}$ offshore $\left(38^{\circ} 37^{\prime} 36^{\prime \prime} \mathrm{N}, 15^{\circ} 04^{\prime} 57^{\prime \prime} \mathrm{E}\right)$ from the land-based observation station. The SM4M was buoyed and connected to a seafloor-mounted weight in the middle of the water to reduce effect from sea current fluctuation (Li, 2017). It was at $7 \mathrm{~m}$ depth, which was $8 \mathrm{~m}$ above the seabed (depth $15 \mathrm{~m}$ ) and $128 \mathrm{~m}$ southwest to the rocks. The sea state was primarily 2 and never exceeded 3 on the Beaufort scale throughout the recording.

\section{B. Acoustic recording}

The SM4M recorded continuously for close to 7 hours at a sampling frequency of $96 \mathrm{kHz}$. The frequency response of the SM4M system is flat between $2 \mathrm{~Hz}$ and $48 \mathrm{kHz}$. The hydrophone was calibrated at the National Physical Laboratory, London.

Ship passage activities were recorded in the Panarea southeastern water channel using the land-based monitoring and interpolated AIS. Ship positions, speeds, and the closest points of approach (CPAs) of the interested ships to the SM4M were evaluated and verified from the AIS data and land-based monitored video. The AIS data and wind speed data were obtained from https://www.marinetraffic.com. The irregularity of 
the AIS points, introduced by the atmospheric conditions and variability in ship AIS transmissions, is corrected and interpolated using the land-based video. The measured acoustic data were manually verified and evaluated from the presence of a single ship according to the ship passage information involving the land-based video, and the AIS data.

\section{Data processing and modelling}

\section{Recorded data}

Here we denote underwater noise as the combination of targeted hydrofoil signature (shipping radiated signal) and the background noise (the noise recorded without visible shipping) (Gen, 2017). The background noise in the channel were measured when no ships were present within $5 \mathrm{~km}$ of the receiver, providing a noise baseline for the area. A data segment of $201 \mathrm{~s}$ duration centered on the CPA was selected for processing. The horizontal distance from the ships to the hydrophone was calculated from the coordinates of the ships and hydrophone. For each $1 \mathrm{~s}$ interval, the time series were processed using a fast-Fourier transform (FFT) and a Hanning window with an FFT length of $f_{s}=96000$ samples and $50 \%$ overlap. The spectrum data were then converted to density levels in $\mathrm{dB}$ re $1 \mu \mathrm{Pa}^{2} / \mathrm{Hz}$. The spectrogram and sound pressure level (SPL) for the measurement period were calculated over the frequency bandwidth of shipping (Fig. 2).

\section{Propagation loss}

To estimate the source level of the hydrofoil noise, we need to calculate the propagation loss (Urick, 2013) in the acoustic channel from the hydrofoil to the hydrophone. In such shallow water, acoustic arrivals are strongly affected by surface/bottom reflections or refraction in the water column (Henson et al., 2014; Li and Zakharov, 2018; Li et al., 2017). While the dominant frequency for the hydrofoil is relatively low $(30-130 \mathrm{~Hz})$, here we apply the parabolic equation model as a proper model to simulate the propagation loss in shallow water (Collins, 1993; Erbe et al., 2012; Tappert, 1977; Williams et al., 2014). The code that we use for the simulation is a modified version of the software AcTUP presented in (Maggi and Duncan, 2005). It takes into account the soundspeed profile (SSP), bathymetry, and bottom properties as well as multipath acoustic propagation. With the measured SSP and estimated attenuation values, we run the parabolic equation to determine the propagation loss at the appropriate source/recorder depth/range locations at each hydrofoil CPAs. The source level is then estimated as the summation of the channel propagation loss and the received sound level.

\section{RESULTS}

\section{A. Received sound level}

Fig. 2 shows the overall appearance of the broadband power spectral density (PSD) of the recorded noise (upper), and the SPL evaluated over the frequency bandwidth $2 \mathrm{~Hz}-48 \mathrm{kHz}$ (lower) in the measurement. The PSD and SPL were averaged in $30 \mathrm{~s}$ windows. The SPL ranged from 122 to $137 \mathrm{~dB}$ re $1 \mu \mathrm{Pa}^{2}$, where four peaks are clearly visible. The four peaks corresponded to the three passages $(12: 28,15: 28$ and 17:30) of two hydrofoils and a conventional powered boat (15:38) as observed. However, a total of twelve ships travelled through the Panarea southeastern water channel with CPA varying between $100 \mathrm{~m}$ and $600 \mathrm{~m}$ to the receiver were observed and identified in the measurement period. Other shipping passages did not show strong elevation of the underwater noise and the background noise level was comparatively stable between the ship passages throughout the measurement period. During each of the four passages, no other vessels were visible from the land-based observation station.

To make it clear that the noise shown in Fig. 2 does not contain significant contributions from the internal self-noise of the hydrophone and recorder, we tested the hydrophone and recorder in the mid-center of a quiet water tank based at University of Southampton, U.K., and measured the sound. When doing so, we found that there is a constant frequency band ${ }^{1}$ indicative of internal noise at $2-5 \mathrm{kHz}$, and the integrated SPL of the self-noise is computed as $81 \mathrm{~dB}$, which means that the internal selfnoise contributes only in part in Fig. 2 in the frequency band of $2-5 \mathrm{kHz}$.

The three hydrofoil noise recordings, shown in Fig. 2 at $12: 28,15: 28$ and 17:30, span a wide range of frequencies (from $10 \mathrm{~Hz}$ to $48 \mathrm{kHz}$ ). The PSD of hydrofoil noise peaked between 30 and $130 \mathrm{~Hz}$, and the SPL peaks measured on the hydrophone exceeded $130 \mathrm{~dB}$ re $1 \mu \mathrm{Pa}$. Another SPL peak was attributed to a conventional boat, and its spectral energy was concentrated in the frequency range $20-800 \mathrm{~Hz}$, where the $\mathrm{PSD}$ is normally over $100 \mathrm{~dB}$ re $1 \mu \mathrm{Pa}^{2} / \mathrm{Hz}$.

Table I describes partial information of the four passages, with the CPAs identified from the land-based observation data and AIS data. Table II describes characteristics of the two hydrofoils, which are the same surfacepiercing (SP) class. The noise radiated from the conventional (displacement based shipping) boat 'ARNONIA' has been used for comparison.

\section{B. Spectral characteristics}

Fig. 3 shows characteristics of the underwater sound recorded over the period of the three hydrofoil passages. Each passage is analysed in a time-scale window of $201 \mathrm{~s}$ centred at CPA. The analysis includes received sound level in frequency bands of $10 \mathrm{~Hz}-1.2 \mathrm{kHz}$ and $30-130 \mathrm{~Hz}$, noting the hydrofoil speed and distance relative to the hydrophone, and SPL. The length of the fast Fourier 


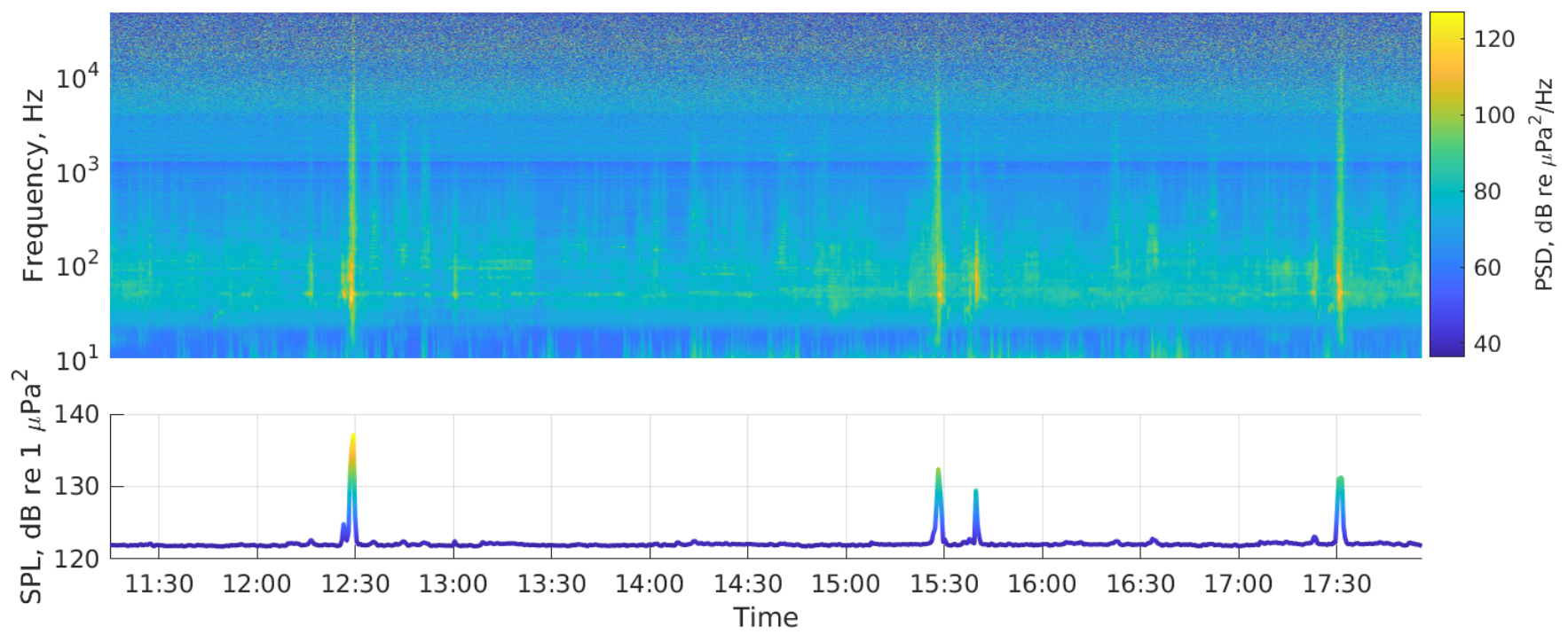

FIG. 2. Upper: Power spectral density (PSD) during the daytime on 14th May 2018 of continuous monitoring. The PSD is averaged in $30 \mathrm{~s}$. Lower: broadband sound pressure level (SPL) for the daytime period, evaluated over the frequency bandwidth $2 \mathrm{~Hz}-48 \mathrm{kHz}$ in the measurement. Four obvious peaks correspond to hydrofoil CALYPSO departure at 12:28, hydrofoil MIRELLA MORACE arrival at 15:28, conventionally powered vessel ARNONIA departure at 15:38, and hydrofoil MIRELLA MORACE departure at 17:30, respectively. Maxima in the SPL data were detected for subsequent comparison to on-land video data, port cruise timetable and AIS data. The time axis shows the local time advanced two hours to the GMT time (color online).

TABLE I. Ship passages of interest at the Panarea southeastern water channel in the daytime of 14 th May 2018.

\begin{tabular}{lccc} 
Time & Ship & direction to port & CPA \\
\hline 12:28 & hydrofoil CALYPSO & heading out & $160 \mathrm{~m}$ \\
15:28 & hydrofoil MIRELLA MORACE & heading in & $340 \mathrm{~m}$ \\
15:38 & conventional boat ARNONIA & heading out & $500 \mathrm{~m}$ \\
17:30 & hydrofoil MIRELLA MORACE & heading out & $340 \mathrm{~m}$ \\
\hline
\end{tabular}

transform (FFT) here is $f_{s}=96 \mathrm{kHz}$, which leads to a frequency resolution of $1 \mathrm{~Hz}$.

\section{Spectrogram}

Fig. 2 shows that the dominant received sound over the broadband range monitored is located at frequencies below $1.2 \mathrm{kHz}$. Consequently, we show the received sound level in the frequency band $[10 \mathrm{~Hz}, 1.2 \mathrm{kHz}]$ in detail in Fig. 3 row 1. While the hydrofoil transitions from displacement to foil-based operation, the source depth was reduced from a deeper position in the water to a depth closer to the sea surface. Note that the depth of the seafloor is $15 \mathrm{~m}$ where the hydrophone was deployed; the seafloor closer to the port tends to be shallower (7$10 \mathrm{~m}$ depth around the port); and the seafloor further from the port tends to be deeper $(30 \mathrm{~m}$ depth at $3 \mathrm{~km}$ southwest to the port).

Fig. 3 row 2 shows the received sound level in an even lower frequency band. Two dominant features shown are time-varying tonal lines around $50 \mathrm{~Hz}$ and $100 \mathrm{~Hz}$. These tonal lines are interpreted to be a result of propeller blade rates and their harmonics (McKenna et al., 2012). The fundamental frequency of the radiated tonal noise increases from $40 \mathrm{~Hz}$ to $50 \mathrm{~Hz}$ at the early stage 2 (speed increasing) as the hydrofoils headed out from the port. This leads to rapidly growing speeds and the lifting of the hydrofoil body/hull from the water. The variability of the levels is attributed to the variability of the hydrofoil operating stages. In the outward heading direction, at low speeds, the wing-like foils are totally submerged in the water. As the speed increases, the foils create lift. At a certain speed, the lift equals to the sum of the ship and passengers' weight. Therefore the ship body/hull comes out of the water. After this dynamic lift, the drag decreases which leads to a better use of power in increasing the speed. At this stage 3 (foil-based shipping), as the hull is no longer submerged in the water, the hydrofoil shipping does not contribute much to the underwater noise (see simulation results in Section III C). 

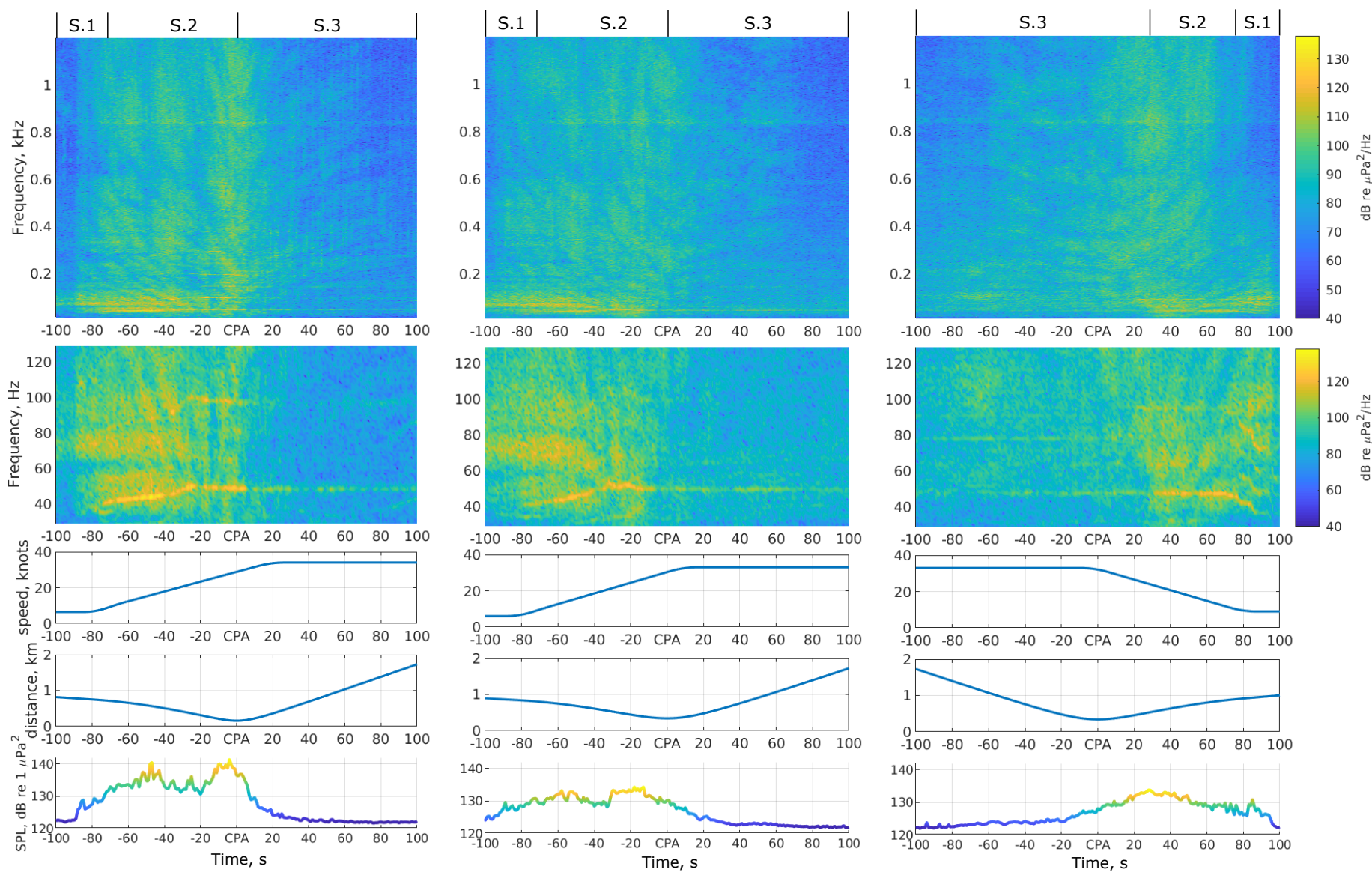

(a)

(b)

(c)

FIG. 3. Characteristics of received sound of the three passages of the two hydrofoils. Integration time $1 \mathrm{~s}$ here. (a) CALYPSO, heading out. (b) MIRELLA, heading out. (c) MIRELLA, heading in. Figures are centered at CPA of the ship to the acoustic recorder. Top figure series show the received sound level $\left[\mathrm{dB}\right.$ re $\left.1 \mu \mathrm{Pa}^{2} / \mathrm{Hz}\right]$ in frequency band $10 \mathrm{~Hz}-1.2 \mathrm{kHz}$ as color using sequential $1 \mathrm{~s}$ spectral averages (Hanning window, FFT length $f_{s}$ samples, and $50 \%$ overlap); second row figure series show sound level in frequency band $30-130 \mathrm{~Hz}$; third row figure series show ship speed to the ground; fourth row figure series show corresponding ship distance to the acoustic recorder; fifth row figure series show SPL of the received sound, where the integration bandwidth for SPL is $10 \mathrm{~Hz}-48 \mathrm{kHz}$. S.1, S.2, S.3 denote 3 hydrofoil operating stages (displacement, transition, and foiling), respectively (color online).

Fig. 4 compares the received sound levels of the hydrofoil CALYPSO at CPA-50 s (early stage 2) and CPA-10 s (end stage 2), and the hydrofoil MIRELLA MORACE at CPA-50 s (early stage 2) and CPA-10 s (end stage 2) in the heading out direction. At the stage 2 , the hydrofoil hull was still in the water. During the dynamic lifting, the fundamental tonal increased from $40 \mathrm{~Hz}$ to $50 \mathrm{~Hz}$. The tonal harmonics showed similar trend, from $80 \mathrm{~Hz}$ to $100 \mathrm{~Hz}$, and from $120 \mathrm{~Hz}$ to $150 \mathrm{~Hz}$.

To compare the noise levels from the hydrofoil passage and conventionally powered vessel (vessel hull is always in the water) passage, and compare noise levels of hydrofoils at different directions of passage as well as background noise in the water area, we present the received sound levels using PSD in Fig. 5. Fig. 5(a) shows that the received noise level of hydrofoil CALYPSO was comparable with that of the conventional boat ARNONIA in the frequency band 30-200 $\mathrm{Hz}$ in the heading out direction from the port. However, below or above this frequency band, the received hydrofoil noise was nearly 15-25 dB higher than that of the conventional vessel ARNONIA. At high frequencies above $3 \mathrm{kHz}$, the noise level of ARNONIA was comparable to the background noise while the hydrofoil noise level was much higher. Fig. 5(b) shows that the received noise levels of the hydrofoil MIRELLA MORACE were comparable in the frequency band of $60 \mathrm{~Hz}-4 \mathrm{kHz}$ in passage directions of heading in and out relative to the port. Hydrofoil noise out of this frequency band in the outwardly heading di- 
TABLE II. Characteristics for both hydrofoils.

\begin{tabular}{ll}
\hline \hline Vessel type & High speed craft (SP hydrofoll) \\
Gross tonnage & 194 \\
Deadweight & $29 \mathrm{t}$ \\
Draught & $4.2 \mathrm{~m}$ \\
Length $\times$ breadth of vessel body & $31.2 \mathrm{~m} \times 7 \mathrm{~m}$ \\
Maximum width of foil wings & $14.5 \mathrm{~m}$ \\
Maximum speed & $36 \mathrm{knots}$ \\
Propulsion & $2 \times 2000 \mathrm{~kW}$ Diesel engines \\
Engines & $\mathrm{MTU} 39616 \mathrm{~V}$ TE $74 \mathrm{~L}-2$ \\
Propeller number & 2 \\
Propeller diameter & $0.7 \mathrm{~m}$ \\
Propeller blades & 3 \\
Propeller depth in displacement/foiling & $4 \mathrm{~m} / 1 \mathrm{~m}$ \\
Shaft RPM in displacement/foiling & $800 / 1000$ \\
Year built & $2005 / 2006$
\end{tabular}

rection was somewhat higher than that in the inwardly heading direction. Both of them were much higher than the background noise level. By comparing the two outbound travels of the two hydrofoils (red curves in the FIG. 5 (a) and (b)), we can see that the PSD measured at the hydrophone when the ship was at the CPA $160 \mathrm{~m}$ was normally about $10 \mathrm{~dB}$ higher than that measured at the CPA $340 \mathrm{~m}$ over the frequency $100 \mathrm{~Hz}$, while they were at similar levels below $100 \mathrm{~Hz}$.

\section{Sound pressure levels}

The sound pressure level (SPL) in the time-scale 201$\mathrm{s}$ window is integrated in the interval of $1 \mathrm{~s}$. Fig. 3 row 5 shows the SPLs of the three passages, from which we can observe two substantial peaks in the heading out case (columns (a)\&(b)) and one substantial peak in the heading in case (column (c)). In the outbound case, the first peak was in the middle of hydrofoil lifting period, and the other is in the end of the speed increasing stage (end stage 2). The noise was concentrated in the frequency band $30-130 \mathrm{~Hz}$ around the first peak, while it spanned over a wider range of frequencies around the second peak. However, the only peak in the heading in case was at the beginning of stage 2 .

The hydrofoils CALYPSO and MIRELLA MORACE, headed out from the port with CPAs of $160 \mathrm{~m}$ and $340 \mathrm{~m}$, respectively. Their SPL peaks were about $141 \mathrm{~dB}$ re $1 \mu \mathrm{Pa}^{2}$ and $135 \mathrm{~dB}$ re $1 \mu \mathrm{Pa}^{2}$. The sound propagation in the channel between the two CPAs resulted in about $6 \mathrm{~dB}$ in peak loss of the noise power. However, for the same hydrofoil MIRELLA MORACE in the passage of both the outbound and inbound directions at the same CPA of $340 \mathrm{~m}$, the peak SPLs were comparable.

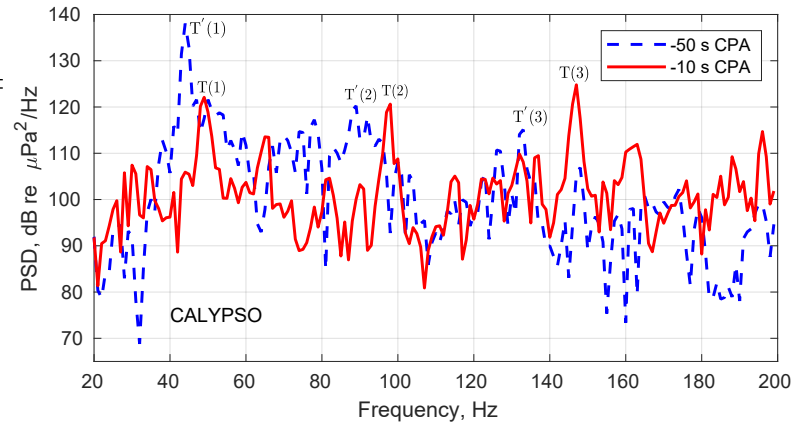

(a)

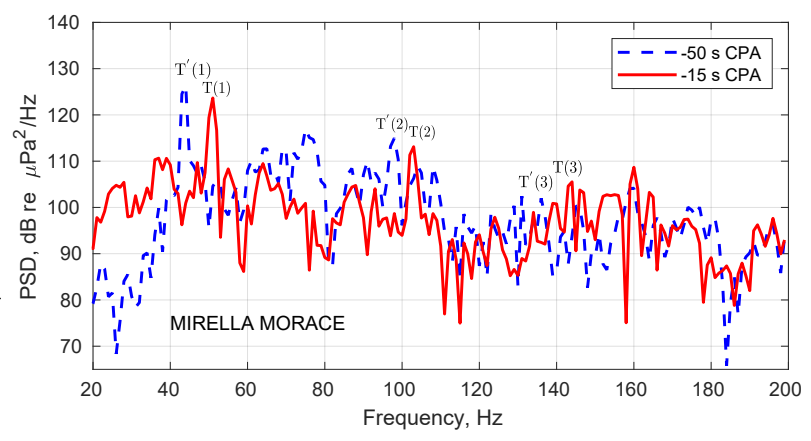

(b)

FIG. 4. Received sound level comparisons in the frequency band $20-200 \mathrm{~Hz}$ of the two hydrofoils in the case of heading in to the port (Fig. 1) show tonal harmonics change from SPL peaks of operating early stage 2 to end stage 2 . Three substantial tonal harmonic components for each example are marked as $\mathrm{T}^{\prime}$ for early stage 2 and $\mathrm{T}$ for end stage 2 . The averaging time for these spectra is $1 \mathrm{~s}$ here. (a) hydrofoil CALYPSO; (b) hydrofoil MIRELLA MORACE.

\section{Noise source level}

The sea state was primarily 2 and thus the sea surface is considered to be flat in the propagation channel modelling. The seabed is considered as an acousto-elastic half space without layers. In this part of the Panarea water area, the seafloor was covered with sand, gravel, and patches of sea grass as photographed by an underwater camera ${ }^{2}$. Similar seabed sediment properties are used from references to define the parameters in our modelling, i.e., the chosen sound speed of the sand and gravel (calcareous sediment) are $1560 \mathrm{~m} / \mathrm{s}$; the density of the sediment that is taken to be $1.8 \mathrm{~g} / \mathrm{cm}^{3}$; and a bottom attenuation coefficient of $0.3 \mathrm{~dB} /$ wavelength is appropriate (Hamilton, 1970; Hampton, 1967; Jackson and Richardson, 2007). The measured SSP is shown in Fig. 6(a). The SSP is strongly downward refracting, such that the normal surface-reflected Lloyd's mirror effects should be washed out in the face of seabed reflections. Thus we apply the calculation of coherent acoustic propagation loss in the function of range and depth (Fig. 6). 


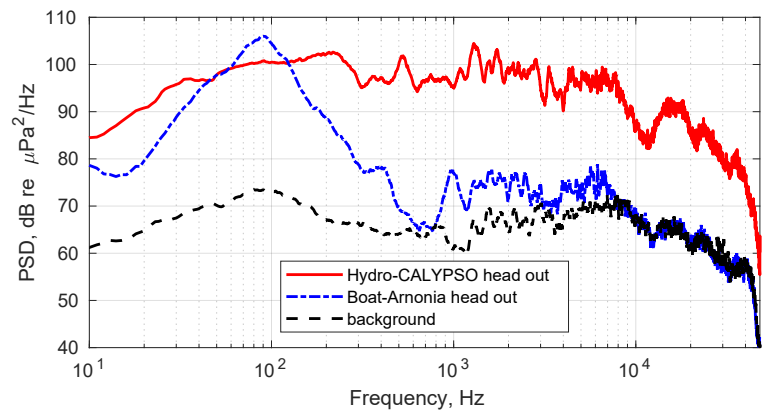

(a)

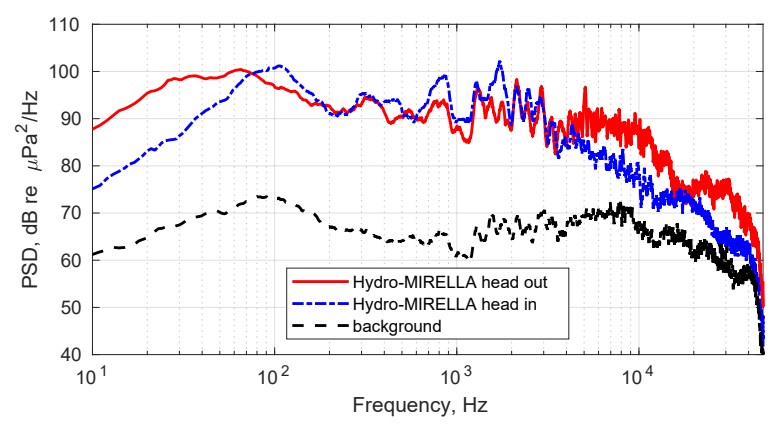

(b)

FIG. 5. Comparison of sound level using PSD. The averaging time for the presented SPL spectra is $1 \mathrm{~s}$. (a) hydrofoil CALYPSO heading out vs. vessel ARNONIA heading out vs. background. (b) hydrofoil MIRELLA MORACE heading out vs. heading in vs. background. The moment for PSD of the heading out hydrofoil CALYPSO was taken at the second SPL peak (CPA-5 s in FIG.3(a) row 5); SPL peak (CPA) for the boat ARNONIA; second SPL peak (CPA-15 s in FIG.3(b) row 5) for the heading out hydrofoil MIRELLA MORACE; and SPL peak (CPA+30 s in FIG.3(c) row 5) for the heading in hydrofoil MIRELLA MORACE. ARNONIA is a passenger ship with a length of $19 \mathrm{~m}$, beam width of $6 \mathrm{~m}$, deadweight of 18 tone, and draught of $2.2 \mathrm{~m}$. It was travelling with a speed of 20 knots, which was much faster than other similar size passenger ships observed on that day. To reduce the random scatter from the measurements in the frequency domain, we applied smoothing on these curves (here we used a moving average filter with a step of 96 points as the smoothing technique), which smears the prominent $50 \mathrm{~Hz}$ and $100 \mathrm{~Hz}$ blade rate tones here.

The noise source is considered as possessing of omnidirectional radiation pattern.

In the parabolic equation modelling, the source depth is set to $4 \mathrm{~m}$ and $1 \mathrm{~m}$ below the sea surface, respectively, to show the sensitivity of the calculation to the source depth, which changes as the hydrofoil transitions from displacement to foiling. The hydrofoil vessel has $4.2 \mathrm{~m}$ draft, the propeller location is about $4 \mathrm{~m}$ depth at slow cruising speeds, rising on foil-based cruising to

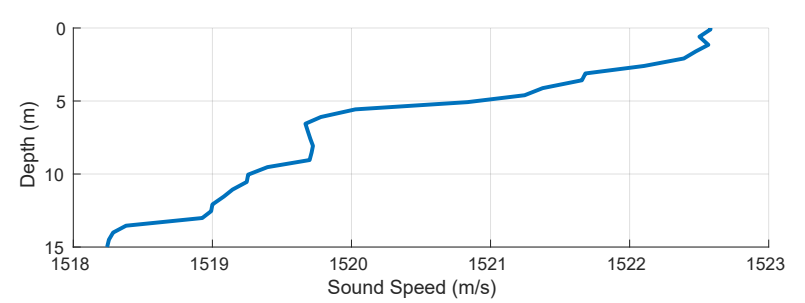

(a) Sound Speed Profile

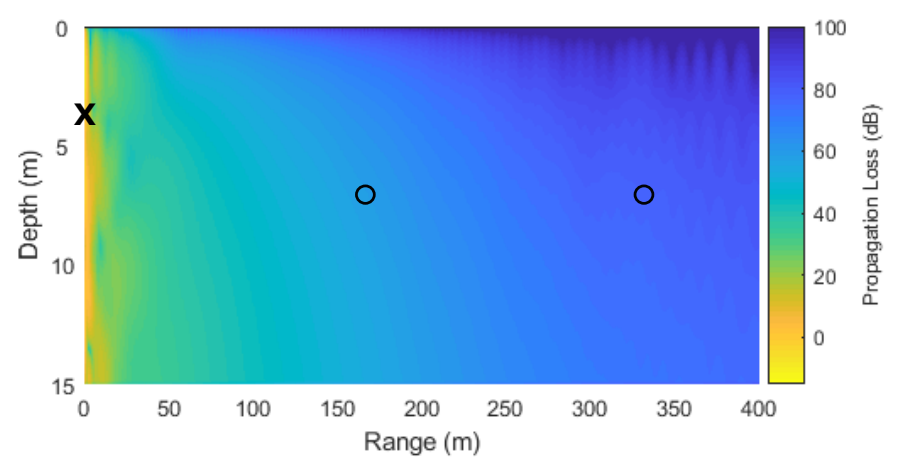

(b) Source depth $4 \mathrm{~m}$

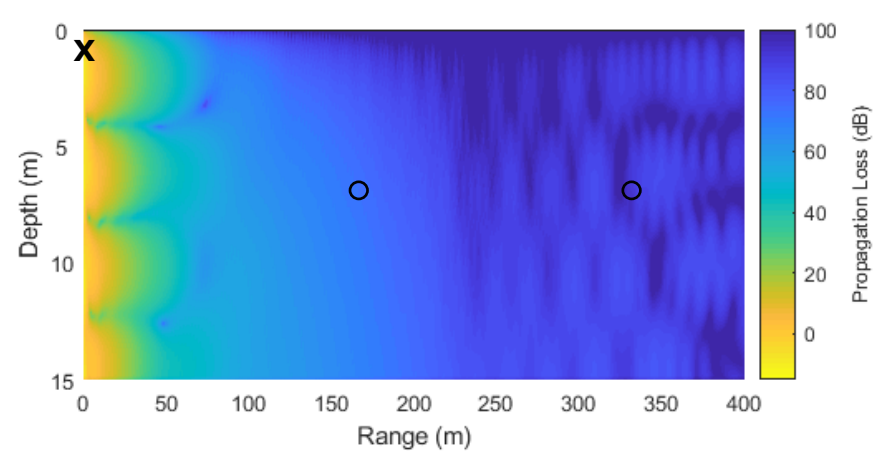

(c) Source depth $1 \mathrm{~m}$

FIG. 6. SSP and calculated propagation loss as a function of depth and range at $50 \mathrm{~Hz}$, for a constant water depth of $15 \mathrm{~m}$, where ' $\mathrm{X}$ ' is the source and ' $\mathrm{O}$ ' is the recorder. (a) Sound-speed profile (SSP) measured in Panarea water area; (b) source depth $4 \mathrm{~m}$; (c) source depth $1 \mathrm{~m}$ (color online).

about $1 \mathrm{~m}$. Note that for accurate noise measurement, the depth should be speed-dependent and the depth of all major noise sources from the hydrofoil should be considered. The receiver was at $7 \mathrm{~m}$ below the sea surface. The horizontal source/receiver distances were $160 \mathrm{~m}$ and $340 \mathrm{~m}$ at closest approach for the hydrofoils CALYPSO and MIRELLA MORACE, respectively.

Fig. 6(b)\&(c) show 2-dimensional modelled coherent propagation loss from the parabolic equation at a frequency of $50 \mathrm{~Hz}$ for the source depth of $4 \mathrm{~m}$ and $1 \mathrm{~m}$, respectively. The propagation loss for the case of $4 \mathrm{~m}$ depth is estimated to be $55 \mathrm{~dB}$ and $70 \mathrm{~dB}$ at the hydrophone distances of $160 \mathrm{~m}$ and $340 \mathrm{~m}$, respectively; 


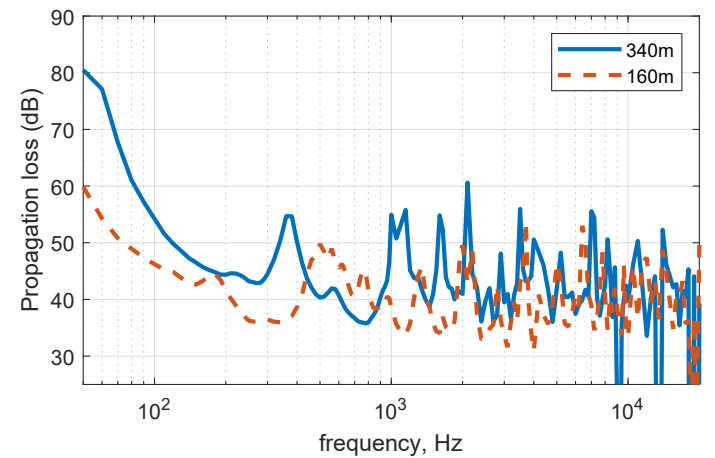

(a) Source depth $4 \mathrm{~m}$

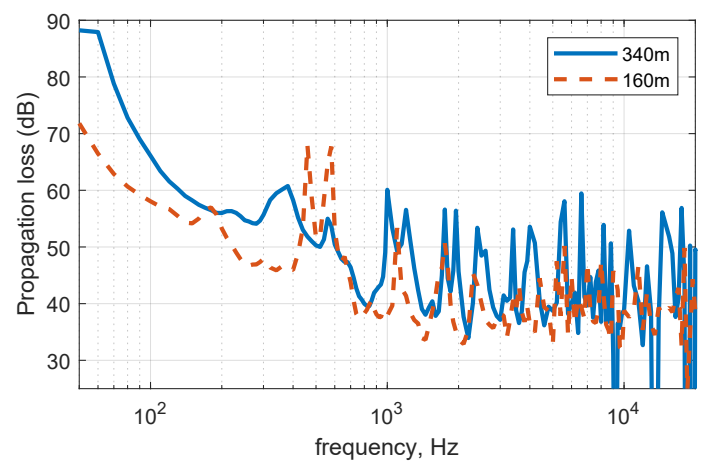

(b) Source depth $1 \mathrm{~m}$

FIG. 7. Calculated propagation loss as a function of frequency, for a constant water depth of $15 \mathrm{~m}$, and a receiver depth of $7 \mathrm{~m}$. (a) source depth $4 \mathrm{~m}$; (b) source depth $1 \mathrm{~m}$.

while in the case of $1 \mathrm{~m}$ source depth the propagation loss is estimated to be $65 \mathrm{~dB}$ and $80 \mathrm{~dB}$ for the two hydrophone distances, respectively. This means that in both source depths of $1 \mathrm{~m}$ and $4 \mathrm{~m}$, the propagation loss at the distance $160 \mathrm{~m}$ can be $15 \mathrm{~dB}$ less than that at the distance $340 \mathrm{~m}$. The modelling result also shows that as the source moves from a depth of $4 \mathrm{~m}$ to a depth of $1 \mathrm{~m}$, the propagation loss can be decreased by $10 \mathrm{~dB}$ at both hydrophone distances of $160 \mathrm{~m}$ and $340 \mathrm{~m}$ in this water area. FIG. $7(\mathrm{a}) \&(\mathrm{~b})$ show the simulated propagation loss at distances $340 \mathrm{~m}$ and $160 \mathrm{~m}$ as a function of frequency for the source depth of $4 \mathrm{~m}$ and $1 \mathrm{~m}$, respectively. As can be seen, the propagation loss (PL) is highly frequency dependent and sound source/recorder position dependent. To correct the measured SPL to equivalent Source Level shown in Table III, we perform a full-frequency-dependent propagation loss correction on the peak SPL as shown in FIG. 2 (time window $30 \mathrm{~s}$ ) with frequency resolution $10 \mathrm{~Hz}$.

To compare source levels of conventional powered vessels with a relatively constant speed, the frequency band 20-1000 Hz may have been enough (McKenna et al., 2012). However, for the non-conventional vessel, such as the hydrofoil, which radiates noise in a much wider frequency band, the $20-1000 \mathrm{~Hz}$ band is not enough. Further, in the area close to a port/harbour, the hydrofoil dynamically changes its operating modes and noise radiation mechanisms, which may make it unsuitable to use the average noise source level around the CPA in a certain range. Nevertheless, to compare the noise source levels of the measured hydrofoils and some existing conventional vessels (McKenna et al., 2012), we calculate the source level integrated in both the frequency bands $20-1000 \mathrm{~Hz}$ and $10 \mathrm{~Hz}-48 \mathrm{kHz}$ as shown in Table III.

At different source depths (1 $\mathrm{m}$ and $4 \mathrm{~m})$, the PL difference is about $10 \mathrm{~dB}$. Therefore, we apply a range of PL on the measured sound level, as we are not sure of the accurate source depth, which can be 2 or $3 \mathrm{~m}$ or so but should be normally in this range. Then we add up the simulated PL and the measured SPL shown in FIG. 2. However, the Source Level shown in TABLE III is estimated in the time window $30 \mathrm{~s}$, which does not show the state ('transition' or 'foiling') to have the highest Source Level. FIG. 3(a)\&(b) row 5 shows two SPL peaks possessing similar levels in the time window $1 \mathrm{~s}$. The PL at the first peak time (transition, assume source depth $1 \mathrm{~m}$ ) is about $10 \mathrm{~dB}$ lower than that at the second peak time (foiling, assume source depth $4 \mathrm{~m}$ ) as can be seen in FIG. 6(b)\&(c) and FIG. 7. Adding the peak levels and the corresponding PL together, the 'foiling' state may show the highest Source Level. However, such an estimation is a coarse estimation due to the channel uncertainties. For a fine source level estimation on the states, measurements at shorter source/recorder distances would be needed.

The source level of the two hydrofoils were estimated to be $179-197 \mathrm{~dB}$ re $1 \mu \mathrm{Pa}$ at $1 \mathrm{~m}$ in the frequency band $20-1000 \mathrm{~Hz}$, and $185-204 \mathrm{~dB}$ re $1 \mu \mathrm{Pa}$ at $1 \mathrm{~m}$ in the wider frequency band $10 \mathrm{~Hz}-48 \mathrm{kHz}$. The length of the conventional vessels used for comparison are 6-10 times of the hydrofoils' length, and the speeds of the conventional ships were $1 / 4-1 / 3$ of the hydrofoil speed at which the highest source level was recorded. Under the two conditions, the estimated hydrofoil source levels were $6 \mathrm{~dB}$ on average higher than that of the large conventional vessels in the band 20-1000 Hz. While taking account of the wider frequency band source level, the source level of the hydrofoils was $11 \mathrm{~dB}$ in average higher than that of the larger Vehicles Carriers and passenger vessels used for comparison.

\section{DISCUSSIONS}

This study described and compared acoustic levels and spectral characteristics from hydrofoils' passages in different directions to a port in a coastal area of the Mediterranean Sea. The characterization of hydrofoil shipping noise is complicated in different passage conditions, particularly near a port/harbour. We have shown that three operating stages are clearly distinguished in the inbound/outbound directions to the port, by the 
TABLE III. Comparison of hydrofoil source level with other ship signatures.

\begin{tabular}{|c|c|c|c|c|c|}
\hline Ship type & Name & $\begin{array}{c}\text { Length } \\
\mathrm{m}\end{array}$ & $\begin{array}{c}\text { Speed } \\
\text { knots }\end{array}$ & $\begin{array}{l}\text { Source level }^{a} \\
(20 \mathrm{~Hz}-1 \mathrm{kHz})\end{array}$ & $\begin{array}{l}\text { Source level }^{\mathrm{a}} \\
(10 \mathrm{~Hz}-48 \mathrm{kHz})\end{array}$ \\
\hline \multirow[t]{3}{*}{ Hydrofoil } & CALYPSO & 31.2 & 30 & $179 \sim 189$ & $185 \sim 195$ \\
\hline & MIRELLA MORACE & 31.2 & 30 & $188 \sim 198$ & $195 \sim 205$ \\
\hline & MIRELLA MORACE & 31.2 & 30 & $187 \sim 197$ & $194 \sim 204$ \\
\hline Container Ships $^{\mathrm{b}}$ & & 294 & 20.6 & 185.0 & \\
\hline Vehicles Carriers $^{\mathrm{b}}$ & & 173 & 15.2 & 180.0 & \\
\hline Bulk Carriers $^{b}$ & & 189 & 13.8 & 185.8 & \\
\hline Product Tankers $^{\mathrm{b}}$ & & 180 & 15.6 & 181.8 & \\
\hline Modern Cargo Ship ${ }^{\mathrm{c}}$ & & 172.9 & 14 & & 190 (wideband) \\
\hline Mid-size Vessel $^{\mathrm{d}}$ & & 38.9 & 14.6 & & 176.4 (wideband) \\
\hline Large-size Vessel $^{\mathrm{d}}$ & & 155.6 & 15 & & 190.8 (wideband) \\
\hline Passenger $^{\mathrm{e}}$ & & 220 & 17.6 & & $183 \pm 3(50 \mathrm{~Hz}-16 \mathrm{kHz})$ \\
\hline
\end{tabular}

a $\mathrm{dB}$ re $1 \mu \mathrm{Pa}$ at $1 \mathrm{~m}$.

b (McKenna et al., 2012).

c (Arveson and Vendittis, 2000).

d (Erbe et al., 2012).

e (Jansen and de Jong, 2017).

nature of their contribution to the underwater noise in sound levels, and tonal components. Hydrofoil passages significantly elevated the underwater noise across a much wider range of frequencies with the hull submerged in the water than did passages of a conventionally powered vessel used for comparison, and the source level of hydrofoil noise was even sometimes comparable to much larger conventional vessels in the coastal water.

\section{A. Noise level}

Analysing the received sound level makes it possible to characterize the contribution of hydrofoil shipping noise relative to underwater noise levels in the Panarea southeastern water channel. In the wide frequency bandwidth of hydrofoil shipping noise $(10 \mathrm{~Hz}-48 \mathrm{kHz})$, we recorded a SPL of the underwater noise during hydrofoil travels in the water area as over $130 \mathrm{~dB}$ re $1 \mu \mathrm{Pa}$ (averaging time $30 \mathrm{~s}$ ) compared to a median of $122 \mathrm{~dB}$ re $1 \mu \mathrm{Pa}$ in the absence of hydrofoil passage. The specific noise radiated by hydrofoil in such a wide frequency range in coastal water may provide reference information for the study of noise exposure in representative habitats (Bertucci et al., 2015; Butler et al., 2016; Vasconcelos et al., 2007), particularly for marine animals communicating using high frequencies, such as dolphins, tooth whales, and porpoises.

\section{B. Use of CPA}

The measurements show that the hydrofoil radiated noise depends strongly on the 'stage' of the hydrofoil operation, with the highest levels occurring during the transition between 'displacement' and 'foiling'. Measure- ments of this radiated noise with a fixed hydrophone depend strongly on the timing of these stages relative to the CPA during the passage of the vessel.

By relating the acoustic data to the CPA of hydrofoils, it was possible to account for multiple peaks in the SPL for which the land-based video monitoring data and AIS data were available. Two substantial peaks of the underwater noise were identified as the hydrofoils were outbound from the port while only one substantial peak when inbound to the port. While even if there are subtle patterns due to seabed reflections underlying the data, the patterns should be significantly different at different CPA distances depending on the method of data analysis.

\section{Acoustic propagation channel}

In this study, the acoustic recorder was positioned in the middle of the water column and may not be necessarily representative of the levels throughout the entire water column (McKenna et al., 2012). The noise levels recorded by it may differ from water column properties during each ship passage (Jensen et al., 2011), the seasonal variations and levels recorded at different range and depth, and the sea currents (Li, 2017; Li et al., 2019b). The modelling of the acoustic propagation channel is helpful to find the noise source level of a vessel, and also can be used to make comparison between events at different ranges.

\section{Study limitations}

Limitations on the characterisation of the hydrofoil shipping noise include the receiver range and depth, channel propagation loss assessment, and the accuracy 
of operating stage conversion of the hydrofoils. During the measurement, several vessels moored in the Panarea port may have radiated noise. Besides, the combined estimation of the CPAs according to the land-based monitoring data and AIS data associated to the received noise may not be accurate enough. However, the shallowwater acoustic propagation is significantly affected by the source/recorder depth and range, and the sea surface and seabed reflection, which result in many uncertainties on the characterisation of the noise sources, e.g., the hydrofoil source noise.

\section{E. Outlook for the future}

There has been increasing awareness of the potential influence of non-conventional vessels on the marine environment, such as the hydrofoils, which radiate noise over a wide range of frequency from several $\mathrm{Hz}$ to tens of $\mathrm{kHz}$. The measurement of the hydrofoil noise provides insight into the elevated underwater noise in the coastal water, and characterization of the sound level in coastal habitats is a necessary step towards understanding how these shipping noises affect marine ecosystems. Further work is needed to more comprehensively measure and characterize hydrofoil noise in both shallow water and deep water with hydrophones deployed at different ranges and depths, and characterize other non-conventional vessels in coastal water.

\section{ACKNOWLEDGMENTS}

We would like to deeply thank the reviewers who have had significantly improved the paper. Funding was provided by the European Unions Horizon 2020 research and innovation programme under the grant agreement number 654462 (STEMM-CCS). We thank the scientific divers Andrea Fogliozzi and Martina Gaglioti for their professional and tireless work. We also thank Prof. Jonathan M. Bull for his skilled organization of the field work.

\footnotetext{
${ }^{1}$ See Supplementary material at [SuppPub1.pdf] for PSD of experimental pool test noise.

${ }^{2}$ See Supplementary material at [SuppPub1.pdf] for the photograph of seafloor in the water channel.
}

(2017). "Underwater acoustics Terminology, ISO 18405:2017(E)," Technical Report 1 (International Organization for Standardization.).

Aktas, B., Atlar, M., Turkmen, S., Shi, W., Sampson, R., Korkut, E., and Fitzsimmons, P. (2016). "Propeller cavitation noise investigations of a research vessel using medium size cavitation tunnel tests and full-scale trials," Ocean Engineering 120, 122135, doi: 10.1016/j.oceaneng.2015.12.040.

Allen, J. K., Peterson, M. L., Sharrard, G. V., Wright, D. L., and Todd, S. K. (2012). "Radiated noise from commercial ships in the gulf of maine: Implications for whale/vessel collisions," J. Acoust. Soc. Am. 132(3), EL229-EL235, doi: 10.1121/1. 4739251.

Andrew, R. K., Howe, B. M., and Mercer, J. A. (2011). "Long-time trends in ship traffic noise for four sites off the north american west coast," J. Acoust. Soc. Am. 129(2), 642-651, doi: 10.1121/ 1.3518770 .

Arveson, P. T., and Vendittis, D. J. (2000). "Radiated noise characteristics of a modern cargo ship," J. Acoust. Soc. Am. 107(1), 118-129, doi: 10.1121/1.428344.

Audoly, C. (2016). "Standardization in underwater acousticscurrent status and on-going actions," in 2nd Australasian Acoustics Conference, Brisbane, Australia, 9-11 November 2016, pp. $1-9$.

Badino, A., Borelli, D., Gaggero, T., Rizzuto, E., and Schenone, C. (2012). "Normative framework for ship noise: present and situation and future trends," Noise Control Engineering Journal 60(6), 740-762, doi: 10.3397/1.3701045.

Bailey, H., Senior, B., Simmons, D., Rusin, J., Picken, G., and Thompson, P. M. (2010). "Assessing underwater noise levels during pile-driving at an offshore windfarm and its potential effects on marine mammals," Marine Pollution Bulletin 60(6), 888-897, doi: 10.1016/j.marpolbul.2010.01.003.

Bertucci, F., Parmentier, E., Berten, L., Brooker, R. M., and Lecchini, D. (2015). "Temporal and spatial comparisons of underwater sound signatures of different reef habitats in Moorea Island, French Polynesia," PloS one 10(9), e0135733, doi: 10. 1371/journal . pone.0135733.

Butler, J., Stanley, J. A., and Butler IV, M. J. (2016). "Underwater soundscapes in near-shore tropical habitats and the effects of environmental degradation and habitat restoration," Journal of Experimental Marine Biology and Ecology 479, 89-96, doi: 10. 1016/j. jembe. 2016.03.006.

Chen, F., Shapiro, G. I., Bennett, K. A., Ingram, S. N., Thompson, D., Vincent, C., Russell, D. J., and Embling, C. B. (2017). "Shipping noise in a dynamic sea: a case study of grey seals in the Celtic Sea," Marine pollution bulletin 114(1), 372-383, doi: 10.1016/j.marpolbul.2016.09.054.

Collins, M. D. (1993). "A split-step Padé solution for the parabolic equation method," The Journal of the Acoustical Society of America 93(4), 1736-1742.

Dahl, P. H., de Jong, C. A., and Popper, A. N. (2015). "The underwater sound field from impact pile driving and its potential effects on marine life," Acoustics Today 11(2), 18-25.

Deleau, M. J., White, P. R., Peirson, G., Leighton, T. G., and Kemp, P. S. (2019). "Use of acoustics to enhance the efficiency of physical screens designed to protect downstream moving European eel (Anguilla anguilla)," Fisheries Management and Ecology doi: $10.1111 /$ fme.12362.

Erbe, C., MacGillivray, A., and Williams, R. (2012). "Mapping cumulative noise from shipping to inform marine spatial planning," J. Acoust. Soc. Am. 132(5), EL423-EL428, doi: 10.1121/1.4758779.

Erbe, C., McCauley, R., McPherson, C., and Gavrilov, A. (2013). "Underwater noise from offshore oil production vessels," J. Acoust. Soc. Am. 133(6), EL465-EL470, doi: 10.1121/1. 4802183.

Fillinger, L., Sutin, A., and Sedunov, A. (2010). "Acoustic ship signature measurements by cross-correlation method," J. Acoust. Soc. Am. 129(2), 774-778, doi: 10.1121/1.3365315.

Gray, L. M., and Greeley, D. S. (1980). "Source level model for propeller blade rate radiation for the worlds merchant fleet," J. Acoust. Soc. Am. 67(2), 516-522, doi: 10.1121/1.383916.

Halliday, W. D., Insley, S. J., Hilliard, R. C., D. Jong, T., and Pine, M. K. (2017). "Potential impacts of shipping noise on marine mammals in the western Canadian Arctic," Marine pollution bulletin 123(1-2), 73-82, doi: 10.1016/j .marpolbul.2017.09.027.

Hamilton, E. L. (1970). "Sound velocity and related properties of marine sediments, North Pacific," Journal of Geophysical Research 75(23), 4423-4446.

Hampton, L. D. (1967). "Acoustic properties of sediments," The Journal of the Acoustical Society of America 42(4), 882-890.

Henson, B., Li, J., Zakharov, Y. V., and Liu, C. (2014). "Waymark baseband underwater acoustic propagation model," in IEEE Underwater Communications and Networking (UComms), pp. 1-5, doi: 10.1109/UComms . 2014.7017132.

Hermannsen, L., Beedholm, K., Tougaard, J., and Madsen, P. T. (2014). "High frequency components of ship noise in shallow water with a discussion of implications for harbor porpoises (phocoena phocoena)," J. Acoust. Soc. Am. 136(4), 1640-1653, doi: 
$10.1121 / 1.4893908$.

Holt, M. M., Noren, D. P., Veirs, V., Emmons, C. K., and Veirs, S. (2009). "Speaking up: Killer whales (orcinus orca) increase their call amplitude in response to vessel noise," J. Acoust. Soc. Am. 125(1), EL27-EL32, doi: 10.1121/1.3040028.

Jackson, D., and Richardson, M. (2007). High-frequency seafloor acoustics (Springer Science \& Business Media).

Jansen, E., and de Jong, C. (2017). "Experimental assessment of underwater acoustic source levels of different ship types," IEEE Journal of Oceanic Engineering 42(2), 439-448, doi: 10.1109/ JOE. 2016.2644123.

Jensen, F. B., Kuperman, W. A., Porter, M. B., and Schmidt, H. (2011). Computational ocean acoustics (Springer Science \& Business Media).

Lani, S. W., Sabra, K. G., Hodgkiss, W. S., Kuperman, W., and Roux, P. (2013). "Coherent processing of shipping noise for ocean monitoring," J. Acoust. Soc. Am. 133(2), EL108-EL113, doi: $10.1121 / 1.4776775$.

Li, J. (2017). "DOA tracking in time-varying underwater acoustic communication channels," in MTS/IEEE OCEANS 2017Aberdeen, 17303460, pp. 1-9, doi: 10.1109/OCEANSE. 2017. 8084563.

Li, J., White, P. R., Bull, J. M., and Leighton, T. G. (2019a). "A noise impact assessment model for passive acoustic measurements of seabed gas fluxes," Ocean Engineering 183(1), 294-304, doi: $10.1016 / j$.oceaneng.2019.03.046.

Li, J., White, P. R., Roche, B., Bull, J. M., Davis, J. W., Leighton, T. G., Deponte, M., Gordini, E., and Cotterle, D. (2019b). "Natural seabed gas leakage -- variability imposed by tidal cycles," in MTS/IEEE OCEANS 2019-Seattle, U.S., pp. 1-6.

Li, J., and Zakharov, Y. V. (2018). "Efficient use of space-time clustering for underwater acoustic communications," IEEE Journal of Oceanic Engineering 43(1), 173-183, doi: 10.1109/JOE. 2017.2688558.

Li, J., Zakharov, Y. V., and Henson, B. (2017). "Multibranch autocorrelation method for Doppler estimation in underwater acoustic channels," IEEE Journal of Oceanic Engineering 43(4), 1099-1113, doi: 10.1109/JOE.2017.2761478.

Maggi, A., and Duncan, A. (2005). "Underwater acoustic propagation modeling software-actup v2. 2l," Centre for Marine Science and Technology, Curtin University, Australia 1-16.

Matveev, K. (2002). "Tone generation on a hydrofoil of a highspeed ship," Ocean Engineering 29(10), 1283-1293, doi: 10 . 1016/S0029-8018(01)00070-1.

McKenna, M. F., Ross, D., Wiggins, S. M., and Hildebrand, J. A. (2012). "Underwater radiated noise from modern commercial ships," J. Acoust. Soc. Am. 131(1), 92-103, doi: 10.1121/1. 3664100 .

McKenna, M. F., Wiggins, S. M., and Hildebrand, J. A. (2013). "Relationship between container ship underwater noise levels and ship design, operational and oceanographic conditions," Scientific Reports 3, 1760, doi: 10.1038/srep01760.

Merchant, N. D., Blondel, P., Dakin, D. T., and Dorocicz, J. (2012a). "Averaging underwater noise levels for environmental assessment of shipping," J. Acoust. Soc. Am. 132(4), EL343EL349, doi: 10.1121/1.4754429.

Merchant, N. D., Pirotta, E., Barton, T. R., and Thompson, P. M. (2014). "Monitoring ship noise to assess the impact of coastal developments on marine mammals," Marine Pollution Bulletin 78(1-2), 85-95, doi: 10.1016/j.marpolbul.2013.10.058.

Merchant, N. D., Witt, M. J., Blondel, P., Godley, B. J., and Smith, G. H. (2012b). "Assessing sound exposure from shipping in coastal waters using a single hydrophone and Automatic Identification System (AIS) data," Marine pollution bulletin 64(7), 1320-1329, doi: 10.1016/j.marpolbul.2012.05.004.

Nedwell, J., Langworthy, J., and Howell, D. (2003). "Assessment of sub-sea acoustic noise and vibration from offshore wind turbines and its impact on marine wildlife; initial measurements of underwater noise during construction of offshore windfarms, and comparison with background noise," Subacoustech Report ref: 544R0423, published by COWRIE.

Nowacek, D. P., Thorne, L. H., Johnston, D. W., and Tyack, P. L. (2007). "Responses of cetaceans to anthropogenic noise," Mammal Review 37(2), 81-115, doi: 10.1111/j.1365-2907.2007. 00104.x.
Parks, S. E., Clark, C. W., and Tyack, P. L. (2007). "Short-and long-term changes in right whale calling behavior: the potential effects of noise on acoustic communication," J. Acoust. Soc. Am. 122(6), 3725-3731, doi: 10.1121/1.2799904.

Piper, A. T., White, P. R., Wright, R. M., Leighton, T. G., and Kemp, P. S. (2019). "Response of seaward-migrating European eel (Anguilla anguilla) to an infrasound deterrent," Ecological engineering 127, 480-486, doi: 10.1016/j.ecoleng.2018.12.001.

Rendell, L., and Gordon, J. (1999). "Vocal response of longfinned pilot whales (Globicephala melas) to military sonar in the Ligurian Sea," Marine Mammal Science 15(1), 198-204, doi: 10.1111/j.1748-7692.1999.tb00790.x.

Richardson, W. J., and Würsig, B. (1997). "Influences of manmade noise and other human actions on cetacean behaviour," Marine \& Freshwater Behaviour \& Phy 29(1-4), 183-209, doi: 10.1080/10236249709379006.

Solan, M., Hauton, C., Godbold, J. A., Wood, C. L., Leighton, T. G., and White, P. (2016). "Anthropogenic sources of underwater sound can modify how sediment-dwelling invertebrates mediate ecosystem properties," Scientific reports 6, 20540, doi: 10.1038/srep20540.

Tappert, F. D. (1977). "The parabolic approximation method," in Wave propagation and underwater acoustics (Springer), pp. $224-287$.

Urick, R. (1983). "Principles of Underwater Sound (Peninsula, Los Altos, CA)," Google Scholar 423.

Urick, R. (2013). Principles of Underwater Sound (4th edition) (PENINSULA PUBLISHING).

Vasconcelos, R. O., Amorim, M. C. P., and Ladich, F. (2007). "Effects of ship noise on the detectability of communication signals in the lusitanian toadfish," Journal of Experimental Biology 210(12), 2104-2112, doi: 10.1242/jeb.004317.

Wales, S. C., and Heitmeyer, R. M. (2002). "An ensemble source spectra model for merchant ship-radiated noise," J. Acoust. Soc. Am. 111(3), 1211-1231, doi: 10.1121/1.1427355.

Williams, R., Erbe, C., Ashe, E., Beerman, A., and Smith, J. (2014). "Severity of killer whale behavioral responses to ship noise: A dose-response study," Marine pollution bulletin $\mathbf{7 9}$ (12), 254-260, doi: 10.1016/j.marpolbul.2013.12.004.

Williams, R., Veirs, S., Veirs, V., Ashe, E., and Mastick, N. (2018). "Approaches to reduce noise from ships operating in important killer whale habitats," Marine pollution bulletin. 139, 459-469, doi: $10.1016 / j$.marpolbul.2018.05.015.

Wittekind, D. K. (2014). "A simple model for the underwater noise source level of ships," Journal of Ship production and design 30(1), 7-14, doi: 10.5957/JSPD.30.1.120052. 
